\title{
Determination of Adenosine, Cordycepin and Ergosterol Contents in Cultivated Antrodia camphorata by HPLC Method
}

\author{
CHIEN-YU CHANG ${ }^{1,2}$, MING-YONG LUE ${ }^{3}$ AND TZU-MING PAN ${ }^{1 *}$ \\ 1. Institute of Microbiology and Biochemistry, National Taiwan University, 1, Sec. 4, Roosevelt Rd., Taipei City 115, Taiwan, R.O.C. \\ 2. Taiwan Sugar Research Institute, Tainan, Taiwan, R.O.C. \\ 3. Department of Cosmetic Science, Chia-Nan University of Pharmacy and Science, Tainan, Taiwan, R.O.C.
}

(Received: March 3, 2005; Accepted: May 26, 2005)

\begin{abstract}
The concentrations of adenosine and cordycepin, 3'-deoxyadenosine in the hot water extract and ergosterol in the ethanol extract of a cultivated Antrodia camphorata were measured by high performance liquid chromatography (HPLC) method. The procedure were carried out on a reversed-phase $\mathrm{C} 18$ column by linear gradient elution, using four eluents as mobile phase and by isocratic elution, using 100\% methanol as mobile phase, respectively. The analysis was completed within 20 min. The application of this method for quantitation of adenosine and cordycepin in 5-L and 100-L fermentation from two A. camphorata strains BCRC 35396 and BCRC 35398 were described. Comparison of adenosine, cordycepin and ergosterol contents were made with different treatment of 700-L fermentation broth.
\end{abstract}

Key words: adenosine, cordycepin, ergosterol, Antrodia camphorata, high performance liquid chromatography (HPLC) method

\section{INTRODUCTION}

Antrodia camphorata, a native species in Taiwan, grows naturally on Cinnamomum kanehirai Hay, a kind camphor tree native to Taiwan only, and is well known as "Niu-chang-chih". This fungus forms fruit bodies that causes brown rot on C. kanehirai ${ }^{(1-3)}$. Aborigines living in Taiwan's mountain ranges have used this fungus as traditional herb for the treatment of food and drug intoxications, diarrhea, abnormal pains, hypertension and liver cancer as Taiwan folk medicine ${ }^{(2,4)}$. The tonic nature of many fungi was also thought to be attributed to the cardiovascular effects of several nucleoside analogues, including adenosine and cordycepin ${ }^{(1,2,4-17)}$. The current price of fresh fruiting bodies of $A$. camphorata is estimated to be US\$ 1500 per $\mathrm{kg}$.

Cordyceps sinensis, a well known medical fungus, has long been used as Chinese folk medicine for a thousand years. Among the two effective bioactive compounds, adenosine induces apoptosis in human leukemia cell and cordycepin is a cytotoxic compound which interferes the synthesis of RNA and DNA ${ }^{(6)}$. The existence of adenosine and cordycepin in A. camphorata was never reported. Ergosterol is the dominant sterol in the membranes of higher fungi ${ }^{(18,19)}$. Ergosterol is rapidly degraded upon cell death and hence is a potential marker of viable biomass. Several studies have measured the ergosterol contents from ectomycorrhizal fungi ${ }^{(19,20)}$. Recently, the technique of ergosterol analysis has gained favor in ecological studies concerned with quantification of viable fungal biomass ${ }^{(21,22)}$. The objective of this study is to

\footnotetext{
* Author for correspondence. Tel: +886-2-23630231 ext. 3813;

Fax:+886-2-23627044; E-mail: tmpan@ntu.edu.tw
}

establish a rapid extraction and rapid analysis procedure of adenosine, cordycepin and ergosterol from different strains of cultivated A. camphorata mycelia.

\section{MATERIALS AND METHODS}

\section{Chemicals}

Adenosine, cordycepin (3'-deoxyadenosine) and ergosterol (5,7,22-ergostatrien-3ß-ol; provitamin D) were purchased from Sigma (St. Louis, MO, USA). Other chemicals were analytical grade.

\section{Strain and Culture Condition}

(I) Organism

Strains of A. camphorata (BCRC 35396 and BCRC 35398) were purchased from the Bioresources Collection \& Research Center. (FIRDI, Hsinchu, Taiwan, ROC).

\section{(II) Inoculum Preparation}

A. camphorata strains BCRC 35396 and BCRC 35398 were cultured and maintained at $26^{\circ} \mathrm{C}$ on $\mathrm{M} 25$ agar plate (Merck, Germany). Conidiospores obtained from the edge of 21-day-old colonies were used as the inoculum source.

\section{(III) Culture Conditions}

The experiments were carried out in 5-L fermentors (Modular Microferm Bench Top Fermentor, Model BIOFLO 
3000, New Brunswick Scientific Co., Inc., New Jersey, USA) at $28^{\circ} \mathrm{C}$. The cultured media of $A$. camphorata strains are shown as the following: glucose $3 \%$, bacto-peptone $1.5 \%$, yeast extract $1.5 \%$, malt extract $1.5 \%, \mathrm{MgSO}_{4} \cdot 7 \mathrm{H}_{2} \mathrm{O}$ $0.03 \%, \mathrm{KH}_{2} \mathrm{PO}_{4} 0.03 \%$ and $\mathrm{K}_{2} \mathrm{HPO}_{4} 0.03 \%$, pH 5.5. The entire fermentor with 3 - $\mathrm{L}$ of culture medium was autoclaved at $121^{\circ} \mathrm{C}$ for $30 \mathrm{~min}$. Three hundred milliliters of 7-day-old shake flask with the same medium were used as inoculum to each fermentor. The inoculum size was $9 \%(\mathrm{v} / \mathrm{v})$ of the final volume. The fermentation conditions were set at agitation of $150 \mathrm{rpm}$ and aeration rate of $1 \mathrm{vvm}$. The experiments were further scale-up to $100-\mathrm{L}$ and $700-\mathrm{L}$ fermentor respectively. The culture conditions of 100-L fermentor were as follows: working volume: $60-\mathrm{L}$; temperature: $28^{\circ} \mathrm{C}$; agitation: 70 $\mathrm{rpm}$; aeration: $1 \mathrm{vvm}$; back pressure: $0.2 \mathrm{~kg} / \mathrm{cm}^{2}$. The culture conditions of 700-L fermentor were as follows: working volume: $400-\mathrm{L}$; temperature: $28^{\circ} \mathrm{C}$; agitation: 60 70 rpm; aeration: $1 \sim 1.2 \mathrm{vvm}$; back pressure: $0.3 \mathrm{~kg} / \mathrm{cm}^{2}$.

\section{Cell Mass Determination}

Cell mass was determined by measuring the dry cell weight of $10 \mathrm{~g}$ suspension taken from the fermentor. The mycelia were collected by centrifugation at 5,200 $\times \mathrm{g}$ for 20 min. Cells were dried at $105^{\circ} \mathrm{C}$ to constant weight.

\section{Extraction and Analysis of Adenosine and Cordycepin from Antrodia camphorata Strains}

One gram of dry cultivated mycelia of A. camphorata were ground into powder and extracted with distilled water $(10 \mathrm{w} / \mathrm{v})^{(13,23,24)}$ followed by incubation in $100^{\circ} \mathrm{C}$ water bath for $1 \mathrm{hr}$. The hot water extract was separated from cells by centrifugation at $20,200 \times \mathrm{g}$ for $10 \mathrm{~min}$. The supernatant was then filtered through $0.45 \mu \mathrm{m}$ membrane filter and stored at $4{ }^{\circ} \mathrm{C}$. The HPLC system was consisted of Waters Model Alliance 2690 and 996 photodiode array detector set at $254 \mathrm{~nm}$ wavelength (Waters, USA). The separations were achieved with a $15-\mu \mathrm{L}$ loop, and a reversed-phase column (Merck LiChrospher 100 RP-18, $5 \mu \mathrm{m}, 4.0 \times 250$ mm I.D.; Darmstadt, Germany) followed by linear gradient elution using eluents $\mathrm{A}, \mathrm{B}, \mathrm{C}$ and $\mathrm{D}\left[\mathrm{A}: \mathrm{H}_{2} \mathrm{O} ; \mathrm{B}: \mathrm{CH}_{3} \mathrm{CN} / \mathrm{MeOH}\right.$ $(1: 1, \mathrm{v} / \mathrm{v})$; $\mathrm{C}: 0.1 \mathrm{~N} \mathrm{HCl} ; \mathrm{D}: 0.1 \mathrm{~N} \mathrm{NH}_{4} \mathrm{H}_{2} \mathrm{PO}_{4}$ (adjusted to $\mathrm{pH} 4.0$ with $\mathrm{H}_{3} \mathrm{PO}_{4}$ )] according to the following A-D profile: $0 \sim 15 \mathrm{~min}, 60 \sim 30 \% \mathrm{~A}, 0 \sim 30 \% \mathrm{~B}, 20 \% \mathrm{C}, 20 \% \mathrm{D}$; $15 \sim 20 \mathrm{~min}, 30 \sim 60 \% \mathrm{~A}, 30 \sim 0 \% \mathrm{~B}, 20 \% \mathrm{C}, 20 \% \mathrm{D}$. The gradient started with $60 \%$ solvent A, $0 \%$ solvent B, $20 \%$ solvent $\mathrm{C}$ and $20 \%$ solvent $\mathrm{D}$ and was linearly decreased to $30 \%$ solvent $\mathrm{A}$, increased to $30 \%$ solvent $\mathrm{B}$ over $15 \mathrm{~min}$. Afterwards, the gradient linearly increased to $60 \%$ solvent A and decreased to $0 \%$ solvent $\mathrm{B}$ in $15 \sim 20 \mathrm{~min}$. It was finally remained at $60 \%$ solvent $\mathrm{A}, 0 \%$ solvent $\mathrm{B}, 20 \%$ solvent $\mathrm{C}$ and $20 \%$ solvent $\mathrm{D}$ for another $5 \mathrm{~min}$. The flow rate was kept at $0.8 \mathrm{~mL} / \mathrm{min}$.

\section{Standard Solution of Adenosine and Cordycepin}

Standard solutions of adenosine were prepared into $0.040,0.067,0.100$ and $0.400 \mathrm{mg} / \mathrm{mL}$ by diluting with distilled water from $4 \mathrm{mg} / \mathrm{mL}$ stock. Standard solutions of cordycepin were prepared into $0.010,0.016,0.024$ and 0.096 $\mathrm{mg} / \mathrm{mL}$ by diluting with distilled water from $0.960 \mathrm{mg} / \mathrm{mL}$ stock. The standard curve was calibrated by plotting the peak area vs. concentration of each standard after HPLC analyses as described above.

\section{Extraction and Analysis of Ergosterol from Antrodia camphorata Strains}

Two grams of dry cultivated mycelia of $A$. camphorata were ground into powder and extracted with ethanol $l^{(19,22,25)}$ followed by incubation in $50^{\circ} \mathrm{C}$ water bath for $1 \mathrm{hr}$. The hot solvent extract was separated from cells by centrifugation at 20,200 $\times \mathrm{g}$ for $10 \mathrm{~min}$. The supernatant was then filtered through $0.45 \mu \mathrm{m}$ membrane filter and was stored at $4^{\circ} \mathrm{C}$. The HPLC system was consisted of Waters Model Alliance 2690 and 996 photodiode array detector set at $271 \mathrm{~nm}$ wavelength (Waters, USA). The separations were achieved with a $15-\mu \mathrm{L}$ loop, a reversed-phase column (Merck LiChrospher 100 RP-18, $5 \mu \mathrm{m}, 4.0 \times 250$ mm I.D.; Darmstadt, Germany) and by isocratic elution, using $100 \%$ methanol as mobile phase. The flow rate of eluent is 1.0 $\mathrm{mL} / \mathrm{min}$.

\section{Standard Solution of Ergosterol}

Standard solutions of ergosterol were prepared into $0.1,0.2,0.3$ and 0.4 and $0.5 \mathrm{mg} / \mathrm{mL}$ by diluting with ethanol from $1 \mathrm{mg} / \mathrm{mL}$ stock. The standard curve was calibrated by plotting the peak area vs. concentration of each standard after HPLC analyses as described above.

\section{Homogenation and Spray-drying from 700-L Fermentation Broth}

The cultured broth of 700-L fermentor with solid content about $13 \%(\mathrm{w} / \mathrm{v})$ was homogenized and sent to the spray-dryer without carrier. The operating condition of spray-drying was as follows: fluid pressure of nozzle at 2.8 $\mathrm{kg} / \mathrm{cm}^{2}$. The inlet and outlet temperature of the spray-dryer were reached $192^{\circ} \mathrm{C}$ and $104^{\circ} \mathrm{C}$, respectively.

\section{RESULTS AND DISCUSSION}

\section{Chromatograms of Adenosine and Cordycepin}

The chromatogram of standard adenosine and cordycepin is shown in Figure 1. The chromatogram of sample analyzed is shown in Figure 2. The retention times of adenosine and cordycepin for the sample were within $10 \mathrm{~min}$. Compared with other methods, this method is rapid, accurate, and highly reproducible ${ }^{(26,27,28)}$. Shiao et al. ${ }^{(28)}$ reported the profiles of nucleosides and nitrogen 


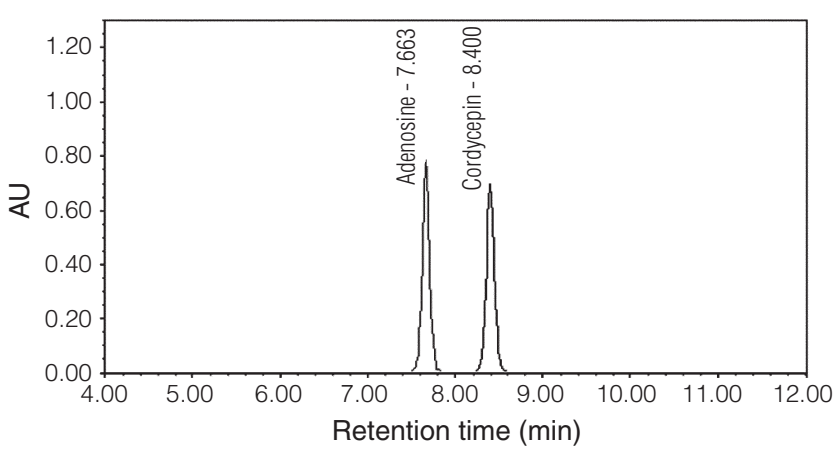

Figure 1. Chromatogram of standard adenosine and cordycepin.

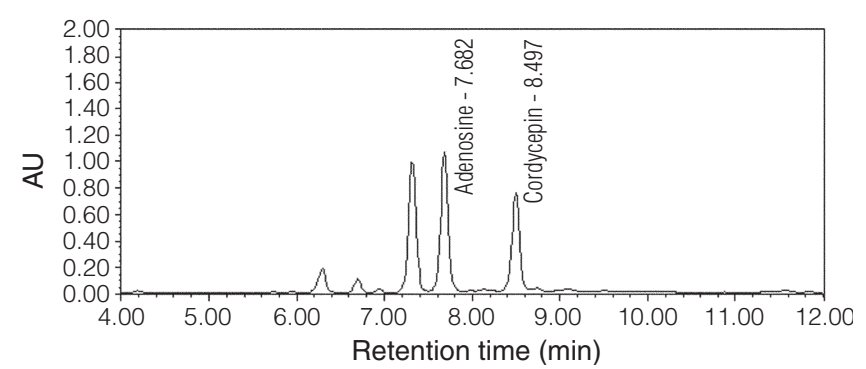

Figure 2. Chromatogram of sample.

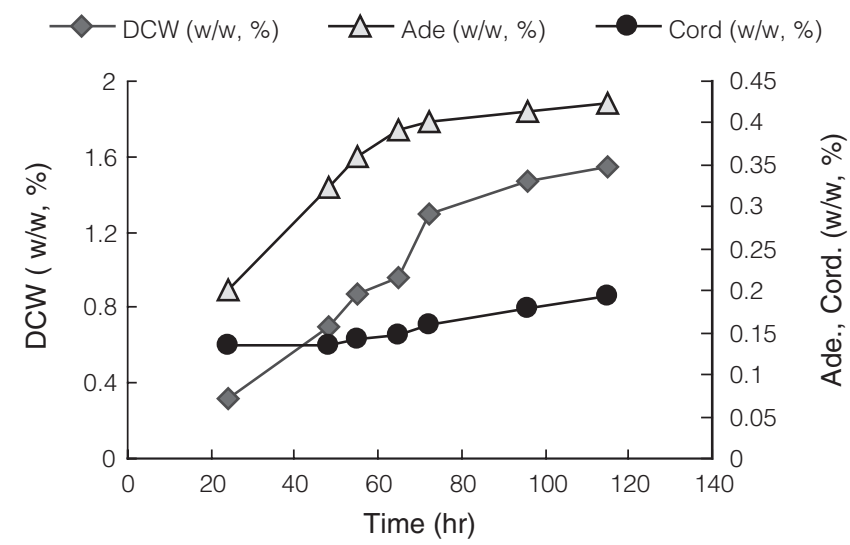

Figure 3. Time course of A. camphorata strain BCRC 35396 cultivated in a 5-L fermentor. DCW: dry cell weight (w/w, \%); Ade: Adenosine (w/w, \%); Cord: cordycepin (w/w, \%).

bases in C. sinensis and several related fungi. Quantitation of adenosine and profile analysis were carried out by reversed-phase high performance liquid chromatography. The retention time of adenosine and cordycepin was 31 min and $33 \mathrm{~min}$, respectively. Edelson et al. ${ }^{(27)}$ used silicabased ion-exchange column for the nucleic acid constituents including adenosine by HPLC method. However, it was not demonstrated clearly how to analyze adenosine and cordycepin simultaneously by gradient elution.

\section{Adenosine and Cordycepin Contents of Cultivated Antrodia camphorata in 5-L Fermentors}

The time course of $A$. camphorata BCRC 35396 strain cultivated in 5-L fermentor is shown in Figure 3. The

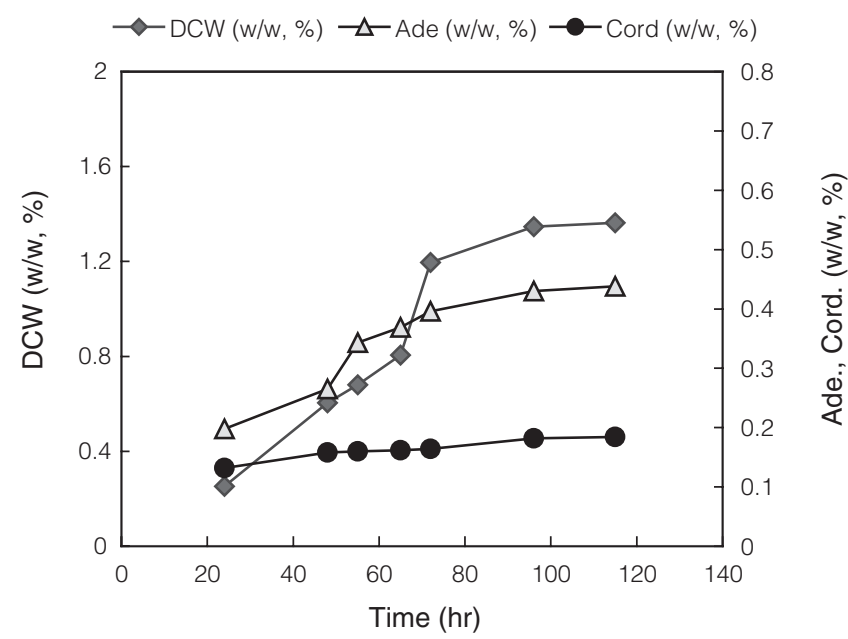

Figure 4. Time course of A. camphorata strain BCRC 35398 cultivation in a 5-L fermentor. DCW: dry cell weight (w/w, \%); Ade: Adenosine (w/w, \%); Cord: cordycepin (w/w, \%).

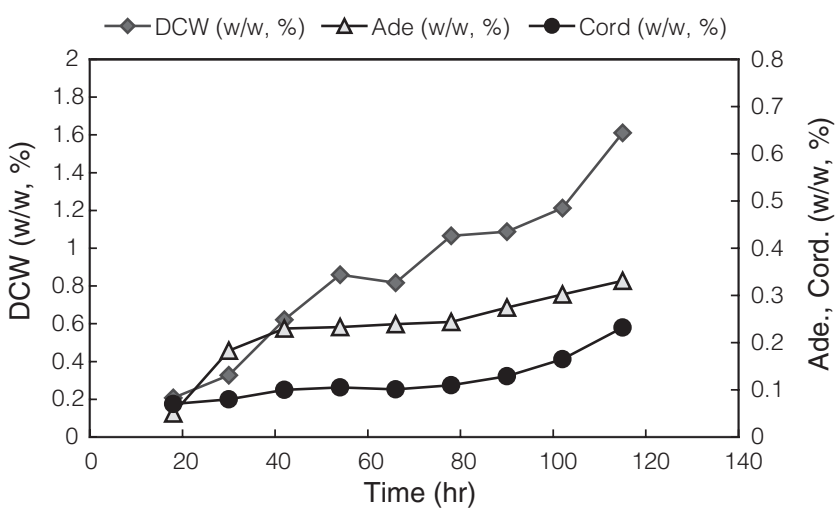

Figure 5. Time course of A. camphorata strain BCRC 35396 cultivation in a $100-\mathrm{L}$ fermentor. DCW: dry cell weight (w/w, \%); Ade: Adenosine (w/w, \%); Cord: cordycepin (w/w, \%).

results revealed that cell growth may reach the stationary phase after $100 \mathrm{hr}$ in 5-L fermentor. The adenosine and cordycepin contents increased significantly within the log phase. Similar results of strain BCRC 35398 are shown in Figure 4. The largest amount of adenosine and cordycepin produced by BCRC 35398 strain were $0.438 \%$ and $0.184 \%$ $(\mathrm{w} / \mathrm{w})$, respectively. There were no significant differences of adenosine and cordycepin contents between the two strains.

\section{Adenosine and Cordycepin Contents of Cultivated Antrodia camphorata in 100-L Fermentors}

The time course of $A$. camphorata BCRC 35396 and BCRC 35398 strain cultivated in 100-L fermentors are shown in Figures 5 and 6 . The cell growth might reach the stationary phase after $120 \mathrm{hr}$ of fermentation. The trend of the adenosine and cordycepin contents within the log phase stage had the similarity found in 5-L fermentors. The results showed that the largest amount of adenosine and cordycepin were $0.382 \%$ and $0.253 \%(\mathrm{w} / \mathrm{w})$ respectively in BCRC 


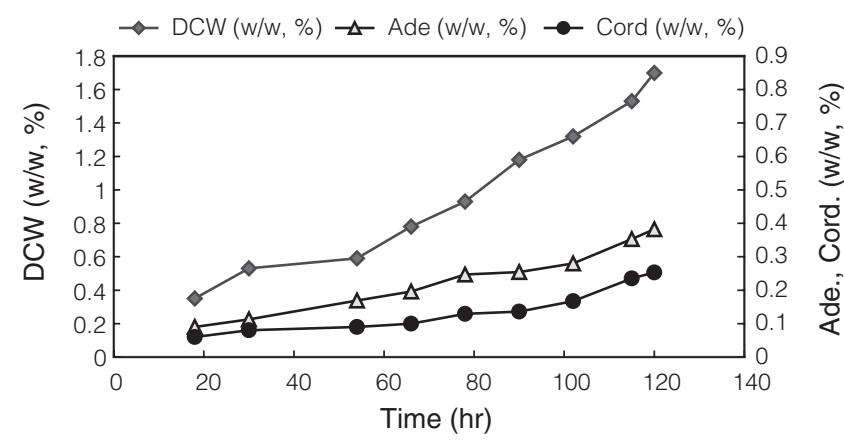

Figure 6. Time course of $A$. camphorata strain BCRC 35398 cultivation in a $100-\mathrm{L}$ fermentor. DCW: dry cell weight (w/w, \%); Ade: Adenosine (w/w, \%); Cord: cordycepin (w/w, \%).

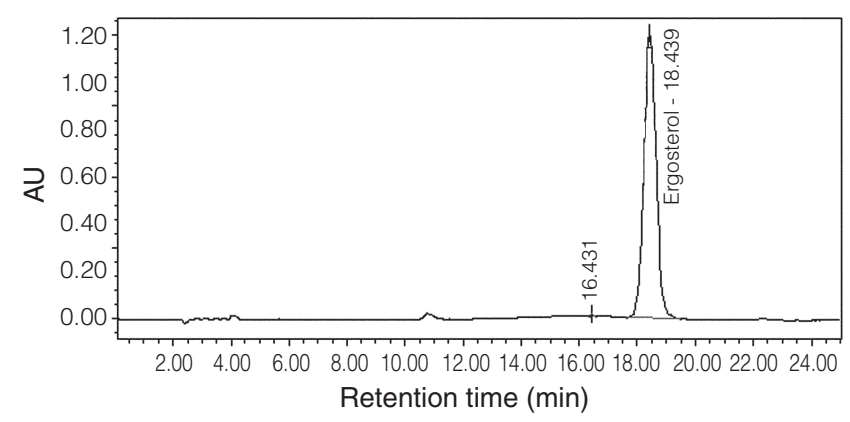

Figure 7. Chromatogram of $0.3 \mathrm{mg} / \mathrm{mL}$ standard ergosterol.

35398 strain cultivation. Dry cell mass reached 1.7\% (w/w) after 5 days of cultivation.

\section{Adenosine, Cordycepin and Ergosterol Contents of Cultivated Antrodia camphorata in 700-L fermentors}

The chromatograms of standard ergosterol and sample ergosterol contents of BCRC 35396 strain cultivated in 700-L fermentors are shown in Figures 7 and 8. The adenosine, cordycepin and ergosterol contents of different types of sample cultivated in 700-L fermentor were compared, such as the dried cell after centrifugation and decanted the supernatant of fermentation broth, the spray-dried powder and the whole dried cell without centrifugation. The results are shown in Table 1. It was revealed that adenosine and cordycepin could be found simultaneously in supernatant and whole cells. The contents of adenosine and cordycepin in broth were higher than that in cells. The spray-dried powder possessed less adenosine and cordycepin than that dried in oven, possibly due to temperature effect. The inlet and outlet temperature of the spray-drier reached $192^{\circ} \mathrm{C}$ and $104^{\circ} \mathrm{C}$, respectively, and the oven temperature maintained at $60^{\circ} \mathrm{C}$ during the drying process. Ergosterol could also be found simultaneously in supernatant and whole cells. The content of ergosterol in broth is less than that in cells. The adenosine, cordycepin and ergosterol contents in the whole dried cell without centrifugation were $5.60 \mathrm{mg} / \mathrm{g}, 5.00 \mathrm{mg} / \mathrm{g}$ and $0.85 \mathrm{mg} / \mathrm{g}$, respectively. The same results were obtained by compared

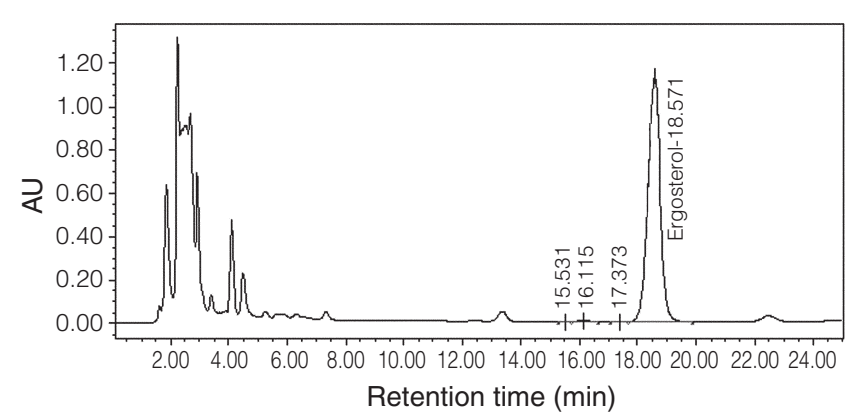

Figure 8. Ergosterol chromatogram of Antrodia camphorata sample.

Table 1. Analysis of adenosine, cordycepin and ergosterol contents in different samples of 700-L fermentation broth

\begin{tabular}{cccc}
\hline Sample & Adenosine $(\mathrm{mg} / \mathrm{g})$ & Cordycepin $(\mathrm{mg} / \mathrm{g})$ & Ergosterol $(\mathrm{mg} / \mathrm{g})$ \\
\hline $\mathrm{Aa}$ & 1.90 & 1.70 & 8.16 \\
$\mathrm{Bb}$ & 4.40 & 4.40 & 0.98 \\
$\mathrm{Cc}$ & 5.60 & 5.00 & 0.85 \\
\hline
\end{tabular}

${ }^{\mathrm{a}}$ The dried cell after centrifugation and decanting the supernatant of fermentation broth.

${ }^{\mathrm{b}}$ The spray-dried powder of fermentation broth.

${ }^{\mathrm{c}}$ The whole dried cell of fermentation broth without centrifugation.

with different types of sample in 100-L fermentor.

The analysis of adenosine, cordycepin and ergosterol produced by $A$. camphorata mycelia using HPLC and reversed-phase $\mathrm{C} 18$ column was developed. The method is rapid, and accurate ${ }^{(23,24,27)}$. The differences between adenosine and cordycepin contents produced by BCRC 35396 and BCRC 35398 strains cultivated in 5-L and 100 -L fermentors were not significant. It was revealed that adenosine and cordycepin could be found simultaneously in supernatant and whole cells. The contents of adenosine and cordycepin in broth were higher than that in cells. On the contrary, the content of ergosterol in broth was less than that in cells. However, comparison of the physiological functions such as antioxidant property, antidote, antiinflammatory activity and protective effect of the mycelia on chronic liver damage were still ambiguous. Studies on their biological functions are underway.

\section{REFERENCES}

1. Andersson, B. E., Tornberg, K., Henrysson, T. and Olsson, S. 2001. Three-dimensional outgrowth of a wood-rotting fungus added to a contaminated soil from a former gasworks site. Bioresour. Technol. 78: 37-45.

2. Chang, T. T. and Chou, W. N. 1995. Antrodia cinnamomea sp. nov. on Cinnamomea kanehirai in Taiwan. Mycol. Res. 99: 756-758.

3. Wu, S. H., Leif, R. and Chang, T. T. 1997. Antrodia camphorata ("niu-chang-chih"), new combination of a medicinal fungus in Taiwan. Bot. Bull. Acad. Sin. 38: 273-275.

4. Cherng, I. H. and Chiang, H. C. 1995. Three new trit- 
erpenoids from Antrodia cinnamomea. J. Nat. Prod. 58: 365-371.

5. Engelhardt, H. and Klinkner, R. 1985. Determination of free formaldehyde in the presence of donators in cosmetics by HPLC and post-column derivation. Chromatographia 20: 559-565.

6. Gamberini, G., Ferioli, V., Zanoli, P., Zeneroli, M. L., Rustichelli, C. and Baraldi, M. 1992. High-performance liquid chromatography method for the analysis of adenosine and some metabolites in the brain tissue of rats. Chromatographia 34: 563-567.

7. Gryllaki-Berger, M., Mugny, C., Perrenoud, D., Pannatier, A. and Frenk, E. 1992. A comparative study of formaldehyde detection using chromotropic acid, acetylacetone and HPLC in cosmetics and household cleaning products. Contact Dermatitis 26: 149-154.

8. Ikumoto, T., Sasaki, S., Namba, H., Toyama, R., Moritoki, H. and Mouri, T. 1991. Physiologically active compounds in the extracts from Tochukaso and cultivated mycelia of Cordyceps and Isaria. Yakugaku Zasshi 111: 504-509.

9. Kiho, T. and Ukai, S. 1995. Tochukaso, Cordyceps species. Food Rev. Int. 11: 231-234.

10. Lai, C. L. 1983. On the production of nucleotides for seasoning from yeast RNA by microorganisms. Ann. Brief Rept. of the Sugar Research. pp. 73-80.

11. Ogata, Koichi. 1964. On the production of nucleotides and the related substances by microorganisms. J. Biochem. 36: 1-14.

12. Michels, J. J. 2001. Improved measurement of formaldehyde in water-soluble polymers by high-performance liquid chromatography coupled with post-column reaction detection. J. Chromatogr. A 914: 123-129.

13. Shiao, M. S., Lin, L. J., Lien, C. Y., Tzean, S. S. and Lee, K. R. 1989. Natural products in Cordyceps. Proc. Natl. Sci. Counc. ROC(A) 13: 382-387.

14. Techel, D. and Braumann, T. 1989. Determination of cyclic nucleotide phosphodiesterase activity in cellular systems by ion-pair reverse-phase liquid chromatography. J. Chromatogr. 483: 427-430.

15. Vanhees, I., Van den Bergh, V., Schilderman, R., De Boer, R., Compernolle, F. and Vinckier, C. 2001. Determination of the oxidation product of the reaction between pinene and hydroxyl radicals by high-performance liquid chromatography. J. Chromatogr. A 915: 75-83.

16. Wu, P. W., Chang, C. C. and Chou, S. S. 2003. Determination of formaldehyde in cosmetics by HPLC method and acetylacetone method. J. Food Drug Anal. 11: 8-15.
17. Yang, J. P. W. 1984. Rapid analysis of nucleotide-5'monophosphate from enzyme degrading yeast ribonucleic acid by reverse-phase high-performance liquid chromatography. Rep. Taiwan Sugar Res. Inst. 103: 25-38.

18. Bermingham, S., Malthy, L. and Cooke, R. C. 1995. A critical assessment of the validity of ergosterol as an indicator of fungal biomass. Mycol. Res. 99: 479-484.

19. Antibus, K. R. and Sinsabaugh, R. L. 1993. The extraction and quantification of ergosterol from ectomycorrhizal fungi and roots. Mycorriza 3: 137-144.

20. Johnson, B. N. and McGill, W. B. 1990. Variations in ergosterol content and ornithine decarboxylase activity of ectomycorrhizal root systems. Plant Soil. 127: 71-79.

21. Newell, S. Y., Miller, J. D. and Fallon, R. D. 1987. Ergosterol content of salt-marsh fungi: Effect of conditions and mycelial age. Mycologia 79: 688-695.

22. Newell, S. Y., Arsuffi, T. L. and Fallon, R. D. 1988. Fundamental procedures for determining ergosterol content of decaying plant material by liquid chromatography. Appl. Environ. Microbial. 54: 1876-1879.

23. Li, S. M., Dai, R. C., Chiang, J. L. and Chen, W. H. 1990. Extraction of adenosine from mycelium of Cordyceps sinensis. China J. Chin. Materia Medica. 16: 40-41.

24. Chen, R. L. C., Wang, Z. S. and Yang, J. P. 1998. Determination of adenosine and cordycepin contents in cultivated Cordyceps by micellar electrokinetic capillary chromatography. Rep. Taiwan Sugar Res. Inst. 161: 4956.

25. Padgett, D. E. and Posey, M. H. 1993. An evaluation of the efficiencies of several ergosterol extraction techniques. Mycol. Res. 97: 1476-1480.

26. Cunha, R. A., Sebastiao, A. M. and Ribeiro, J. A. 1989. Separation of adenosine 5'-triphosphate and its degradation products in innervated muscle of the frog by reverse-phase high-performance liquid chromatography. Chromatographia 28: 610-612.

27. Edelson, E. H., James, G. L., Timothy, W. and Seth, R. A. 1979. Ion-exchange separation of nucleic acid constituent by high-performance liquid chromatography. J. Chromatogr. 174: 409-419.

28. Shiao, M. S., Wang, Z. N., Lin, L. J., Lien, J. Y. and Wang, J. J. 1994. Profiles of nucleosides and nitrogen bases in Chinese medicinal fungus Cordyceps sinensis and related species. Bot. Bull. Acad. Sin. 35: 261-267. 